\title{
Effect of vestibular adaptation exercises on chronic motion sensitivity: a randomized controlled trial
}

\author{
Danah Alyahya', Eric G. Johnson ${ }^{1 *}$, Noha S. Daher ${ }^{2}$, Shilpa B. Gaikwad'1, Sukrut Deshpande' ${ }^{1}$, Tim K. Cordett ${ }^{1}$ and Lisa Zidek ${ }^{3}$
}

*Correspondence: ejohnson@llu.edu

'Department of Physical Therapy, Loma Linda University, California, USA.

2Department of Allied Health Studies, Loma Linda University, California, USA.

${ }^{3}$ Loma Linda University Medical Center, California, USA.

\begin{abstract}
Background: Dizziness is one of the most common complaints reported to primary care physicians. It is often associated with vestibular dysfunction and typically impacts postural stability. Motion sickness, or motion sensitivity, is stimulated by abnormal spatial orientation and is a common symptom related to dizziness and postural instability. The main cause of the motion sensitivity is aberrant sensory input from the visual, vestibular and somatosensory systems. The aim of this study was to measure the effect of vestibular adaptation exercises on postural stability in young healthy adults with subjective awareness of chronic motion sensitivity.

Methods: Fifty healthy male and female participants between 20 to 40 years of age with chronic motion sensitivity were randomly assigned to either an experimental or control group. Postural stability measurements were taken at baseline and after 6 weeks using computerized dynamic posturography with immersion virtual reality. The experimental group performed daily vestibular adaptation exercises for 6 weeks. The control group was asked to avoid adding any new activities until post assessment to minimize additional vestibular system stimulation.

Results: There was no significant difference between the two groups at baseline in terms of mean age, height, weight, BMI or baseline postural stability scores ( $p>0.05$ ). Significant differences in mean postural stability scores were observed post intervention in both groups but larger improvements were detected in the experimental group $(\mathrm{p}=0.002)$.

Conclusions: Minimal dosage of vestibular adaptation exercises improved postural stability in younger adults with chronic motion sensitivity. Additionally, familiarity of the testing environment during post-test measurements may have contributed to improvements in the control group over time; however, changes were greater in the experimental group.
\end{abstract}

Keywords: Motion sensitivity, postural stability, vestibular rehabilitation, vestibular adaptation exercises

\section{Introduction}

Dizziness is one of the most common complaints reported to primary care physicians [1], which affects $20 \%$ to $30 \%$ of persons in the general population [2]. It is often associated with vestibular dysfunction and typically impacts postural stability [3]. Motion sickness, or motion sensitivity, is stimulated by abnormal spatial orientation and is a common symptom related to dizziness and postural instability [4]. Gender, age, psychological status and the environment can influence motion sensitivity and postural stability [5]. Many otherwise healthy people experience motion sensitivity during activities including riding roller coasters, boat rides, and/or reading in moving vehicles. As a result, they often avoid these activities because it produces motion sensitivity symptoms including dizziness, nausea, imbalance, and/or blurry vision $[5,6]$. Additionally, healthy people commonly experience postural instability when exploring their surrounding visual environment while standing on unstable surfaces or when in virtual reality environments $[6,7]$. 
Simulated virtual reality and related technologies have been used to demonstrate the relationship between motion sensitivity and postural stability [8]. Akiduki et al., reported that motion sensitivity and postural instability are caused by a visual-vestibular conflict that can be reproduced in virtual reality environments [4].

Akin and Davenport describe motion sensitivity as "a dis turbing sense of vertigo or dizziness associated with head movement" that is often the result of vestibular dysfunction [9]. The vestibular system is located in the inner ear and is comprised of three semicircular canals, the utricle and saccule [10]. The vestibular system, along with the visual and somatosensory systems, are the primary systems contributing to motion and postural stability. The afferent input from these systems is processed in the vestibular nuclear complex and coordinates the vestibulo-ocular reflex (VOR) and vestibulospinal reflex, respectively [10]. The VOR maintains stability of the image on the retina during head motions by producing compensatory eye movements for gaze stability [11-14]. The vestibulo-spinal reflex maintains postural stability through the musculoskeletal system during functional activities $[15,16]$. Improvement of the VOR can be achieved through vestibular adaptation exercises [17].

Several investigators have reported on the relationship between vestibular dysfunction and the effect of vestibular adaptation exercises on postural stability and dizziness [18-20]. Giray et al., reported significant improvements in symptoms, disability, balance, and postural stability after performing vestibular adaptation exercises in patients with chronic unilateral vestibular dysfunction [18]. According to Hall et al., patients with unilateral vestibular dysfunction had decreased fall risk after performing vestibular adaptation exercises [19]. Additionally, Morimoto et al., used vestibular adaptation exercises to improve gaze stability and postural stability after three weeks in healthy young adults [20]. To the best of our knowledge, the effects of the adaptation exercise on postural stability in healthy young adults with sub-clinical chronic motion sensitivity have not been investigated. Therefore, the purpose of this study was to measure the effects of vestibular adaptation exercises on postural stability in healthy young adults with sub-clinical chronic motion sensitivity. The hypothesis was that vestibular adaptation exercises would improve postural control during virtual reality immersion in participants with chronic motion sensitivity.

\section{Methods}

Fifty healthy adults between 20 and 40 years of age with sub-clinical chronic motion sensitivity were recruited for this randomized controlled trial. Participants were recruited using flyers that were posted at our university and by word of mouth. Sub-clinical chronic motion sensitivity was operationally defined as a history of avoiding activities causing dizziness, nausea, imbalance, and/or blurred vision without having a related medical diagnosis. Participants were included in the study if they reported avoiding activities such as reading while a passenger in a moving vehicle, driving on winding roads, boats, airplanes, horseback riding, roller coaster rides and quick movements due to symptoms consistent with motion sensitivity. Participants were excluded if they were currently taking medications causing dizziness or imbalance or had cervical spine orthopedic impairments, vestibular impairments or any neurological pathology. The Loma Linda University Institutional Review Board approved the study. All participants signed an informed consent prior to their beginning the study.

Participants were randomly assigned to either an experimental or control group using a random number table. The experimental group received vestibular adaptation exercises. Both groups received postural stability measurements at baseline and after six weeks using computerized dynamic posturography with immersion virtual reality (CDP-IVR) [21]. Additionally, the experimental group had a follow-up assessment at three weeks post-baseline to progress their vestibular adaptation exercises as tolerated. Participants in the experimental group received daily-automated e-mails using a Qualtrics on-line survey reminding them to perform their exercises. We asked the control group to live their life normally and to avoid adding any new activities that required repeated head movement.

The Bertec Balance Advantage CDP-IVR was used to measure postural stability by calculating center of gravity displacements through strain gauges in the forceplate [22-25]. Postural stability was measured under two conditions. Condition 1 measured postural stability on a stable forceplate with eyes open and focusing on a virtual reality infinite tunnel (Figure 1). The infinite tunnel provided the visual illusion that participants were moving towards the tunnel in an anterior

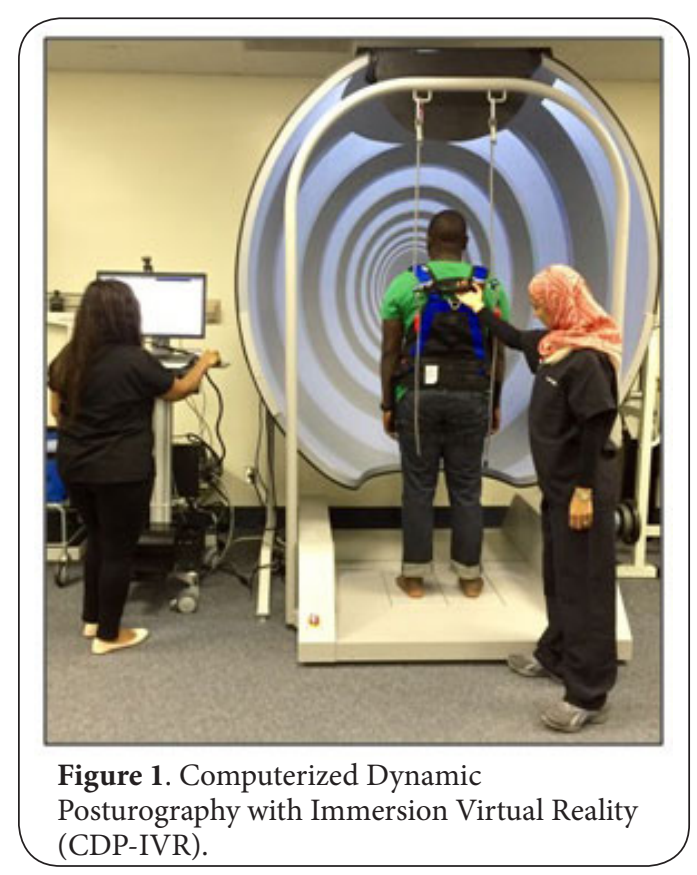


direction. Condition 2 measured postural stability on an unstable forceplate with eyes open focusing on the virtual reality infinite tunnel. Each condition lasted twenty seconds and was repeated three times and an average was calculated.

The Bertec Balance Advantage CDP-IVR calculates postural stability and generates an equilibrium score in the following manner: Signals from the subjects' effort to maintain balance are sampled and analyzed at $1000 \mathrm{Hertz}$ and sway path is computed. The testing protocol calculates the sway path with equilibrium scores quantified by how well the subjects sway remains within the expected angular limits of stability during each testing condition. The following formula was used to calculate the equilibrium score: Equilibrium Score $(E S)=([12.5$ degrees-(the taMAX-the taMIN)]/12.5degrees)*100. The ES uses $12.5^{\circ}$ as the normal limit of the anterior-posterior sway angle range, taMAX is theta maximum and taMIN is theta minimum. Sway angle was calculated as follows: Sway Angle $=\arcsin \left(\mathrm{COG} y /\left(.55^{*} \mathrm{~h}\right)\right)$ where $\mathrm{y}=$ anterior-posterior sway axis and $h=$ the subject's height in [cm or inches]. The inverse Sin of the center of gravity was divided by $55 \%$ of a person's height. Subjects exhibiting little sway will achieve equilibrium scores near 100, while subjects whose sway approaches their limits of stability will achieve scores near zero.

Vestibular adaptation exercises have been shown to improve function of the VOR through visual fixation on a target during head movement "head-eye coordination" $[17,26,27]$. Participants in the experimental group performed the vestibular adaptation exercises one time daily for 5 minutes (Figure 2 and Appendix 1).

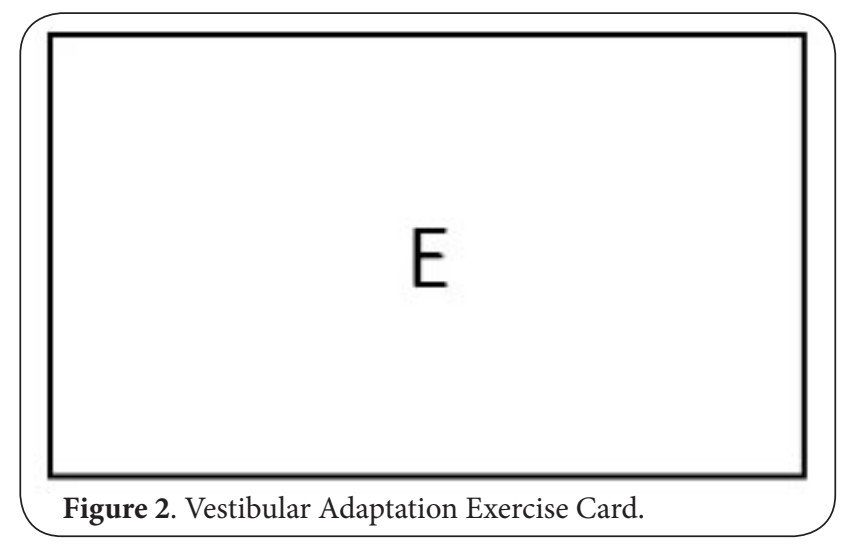

\section{Statistical analysis}

Sample size was calculated using a medium effect size of 0.50 between the experimental and control groups, a power of 0.80 and the level of significance was set at 0.05. Data was analyzed using SPSS Statistics Grad Pack 22.0 PREMIUM for windows. Descriptive statistics were used to summarize the data. Data was reported as mean \pm standard deviation (SD) for quantitative variables and frequency and percentage for categorical variables. Normality of quantitative variables was examined using Kolmogorov Smirnov test and box plots. To compare means of height, weight, and body mass index (BMI) between the experimental and control groups at baseline, an independent t-test was conducted. Mean age and CDPIVR for all conditions (1, 2, and average) by group type were compared using Mann-Whitney $U$ test. The distribution of gender by group was examined using Fisher's Chi-square test. To investigate the effect of the intervention on the outcome measures over time, a $2 \times 2$ mixed factorial ANOVA was conducted. The level of significance was set at $p \leq 0.05$.

\section{Results}

There was no significant difference between the experimental $(\mathrm{N}=26)$ and the control group $(\mathrm{N}=24)$ in terms of mean age, height, weight, BMI, the CDP-IVR scores for conditions 1, 2, and average at baseline $(p>0.05)$. Seventeen participants (70.8\%) in the experimental group were females compared to 17 participants $(65.4 \%)$ in the control group $(\mathrm{p}=0.77)$ (Table 1$)$.

In the experimental group, there was no significant difference in mean CDP-IVR score between baseline and six weeks later for condition $1(90.4 \pm 1.2$ vs. $87.3 \pm 1.7, p=0.08)$ (Figure 3), significant difference in condition 2 (54.2 \pm 4.5 vs. $39.9 \pm 4.8, p=0.001$ ) (Figure 4), and average of the two conditions $(72.3 \pm 2.5$ vs. $63.6 \pm 2.9, p=0.002$ ) (Figure 5$)$. However; in the con-
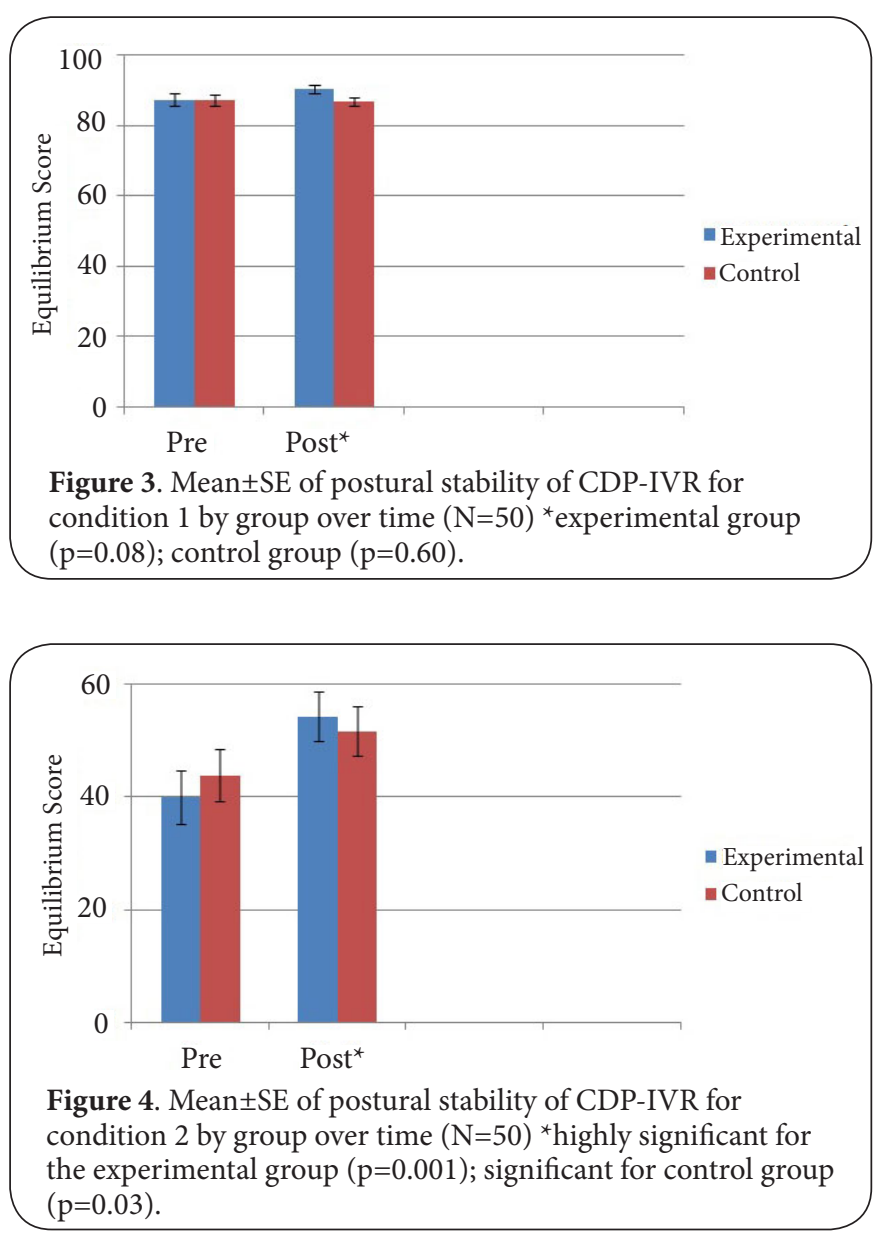


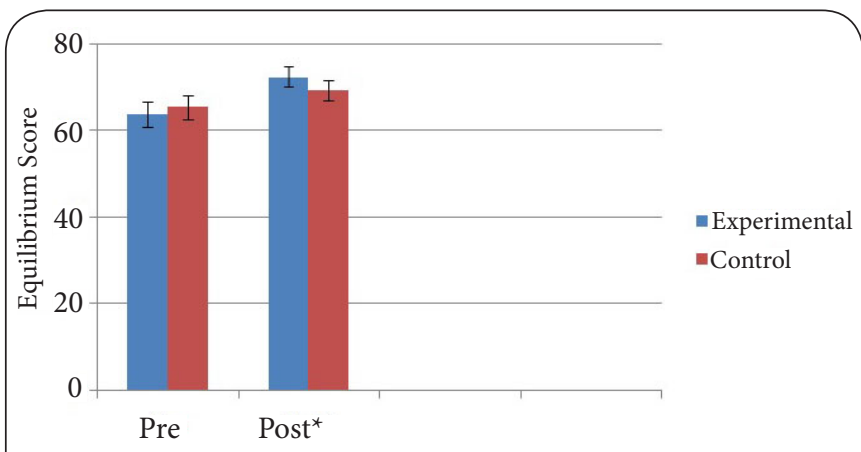

Figure 5. Mean \pm SE of postural stability of CDP-IVR for condition average by group over time $(\mathrm{N}=50){ }^{\star}$ highly significant for the experimental group $(\mathrm{p}=0.002)$; significant for control group $(\mathrm{p}=0.02)$.

Table 1. Mean (SD) of general characteristics $(\mathrm{N}=50)$.

\begin{tabular}{llll}
\hline & $\begin{array}{l}\text { Experimental } \\
\left(\mathbf{N}_{1}=\mathbf{2 6}\right)\end{array}$ & $\begin{array}{l}\text { Control } \\
\left(\mathbf{N}_{2}=\mathbf{2 4}\right)\end{array}$ & P-value $^{\mathrm{a}}$ \\
\hline Female; n (\%) & $17(70.8)$ & $17(65.4)$ & 0.77 \\
${\text { Age }(\text { years })^{\mathrm{b}}}^{\mathrm{c}}$ & $27.3(4.0)$ & $28.4(3.9)$ & 0.22 \\
Height (inches) & $65.3(3.6)$ & $65.2(3.9)$ & 0.90 \\
Weight $(\mathrm{lb})$ & $146.1(33.8)$ & $143.2(24.9)$ & 0.73 \\
BMI $\left(\mathrm{kg} / \mathrm{m}^{2}\right)$ & $23.9(3.9)$ & $23.7(3.3)$ & 0.83 \\
CDP-IVR condition $1^{\mathrm{b}}$ & $87.3(9.6)$ & $87.1(6.6)$ & 0.54 \\
CDP-IVR condition 2 ${ }^{\mathrm{b}}$ & $39.9(25.7)$ & $43.8(21.6)$ & 0.34 \\
CDP-IVR average $^{\mathrm{b}}$ & $63.6(16.2)$ & $65.4(12.4)$ & 0.28 \\
\hline
\end{tabular}

Abbreviation: SD: Standard deviation; CDP-IVR: Computerized Dynamic Posturography with Immersion Virtual Reality Equilibrium Score.

andependent t-test; ' Mann-Whitney U test; 'Fisher's Chi-Square

trol group, there was a significant difference in mean CDP-IVR score post versus pre for condition 2 ( $51.7 \pm 4.3$ vs. $43.8 \pm 4.6$, $\mathrm{p}=0.03)$, and average of the two conditions $(69.3 \pm 2.3 \mathrm{vs}$. $65.4 \pm 2.8, p=0.02$ ) but not for condition $1(p=0.60)$ (Table 2).

When comparing the mean CDP-IVR score between the experimental and control groups, there was a significant difference between baseline and six weeks later for condition 1 only ( $p=0.03$ ) (Table 2). Results indicated the 894 out of 928 responded "yes" on daily exercise reminders through
Qualtrics program for assessment of compliance with the home exercise program (96\%).

\section{Discussion}

The purpose of this study was to measure the effect of vestibular adaptation exercises on adults with sub-clinical chronic motion sensitivity. Postural stability was measured using CDP-IVR. Results supported the hypothesis that vestibular adaptation exercises would improve postural stability in participants with a history of sub-clinical chronic motion sensitivity.

Motion sensitivity has been defined as "a disturbing sense of vertigo or dizziness associated with head movement" that is often caused by vestibular dysfunction [9]. Furthermore, Akiduki et al., reported that motion sensitivity and postural instability are caused by a visual-vestibular conflict [4]. Specifically, the authors suggest an over-reliance on the visual system with a residual deficit of the vestibular system.

Significant improvements in symptoms, disability, balance, postural stability, and fall reduction have been reported after performing vestibular adaptation exercises in patients with vestibular dysfunction $[18,19]$. Although the population in the current investigation did not have medically diagnosed vestibular dysfunction, they did report chronic motion sensitivity causing them to avoid certain activities. The authors suggest a sub-clinical vestibular dysfunction exists in some people with undiagnosed chronic motion sensitivity. Given the evidence supporting vestibular adaptation exercises improving vestibular dysfunction, the authors proposed strengthening the vestibular system using adaptation exercises in the experimental group and measuring the effects of postural stability, which is a component of motion sensitivity. The use of CDP-IVR provided a visually challenging sense of moving for study participants with a potential over-reliance on their visual system.

Because of the visually challenging environment caused by the CDP-IVR, familiarization of the testing conditions may explain the improvements observed in both experimental and control groups time [28]. However; the averaged results after 6 weeks between both test conditions and between groups was greater in the experimental group.

Limitations include not using a validated motion sensitivity subject report to correlate subjective and objective findings in adults with chronic motion sensitivity. Akiduki et al., indicated that there was a variance between "subjective reports of

Table 2. Mean (SE) of postural stability (ES) for both groups by condition over time ( $\mathrm{N}=50$ ).

\begin{tabular}{llllllll}
\hline Group & \multicolumn{3}{c}{ Experimental } & \multicolumn{3}{c}{ Control } \\
\hline & Pre & Post & P-value $^{\mathbf{a}}$ & Pre & Post & P-value $^{\mathbf{a}}$ & P-value $^{\mathbf{b}}$ \\
\hline Condition 1 & $87.3(1.7)$ & $90.4(1.2)$ & 0.08 & $87.1(1.6)$ & $86.9(1.2)$ & 0.60 & 0.03 \\
Condition 2 & $39.9(4.8)$ & $54.2(4.5)$ & 0.001 & $43.8(4.6)$ & $51.7(4.3)$ & 0.03 & 0.51 \\
Condition Av & $63.6(2.9)$ & $72.3(2.5)$ & 0.002 & $65.4(2.8)$ & $69.3(2.3)$ & 0.02 & 0.29 \\
\hline
\end{tabular}

Abbreviations: SE: Standard error; ES: Equilibrium Score); Av: Average

${ }^{a} \mathrm{P}$-values for the null hypothesis that there is a no significant difference between pre and post

${ }^{b} \mathrm{P}$-values for the null hypothesis that there is a no significant difference between the 2 groups 
motion sickness or balance and objective postural instability" [4]. However, Cobb and Nichols reported a strong correlation between self-reported symptoms of simulator sickness and between postural instability and a self-reported of motion sickness symptoms [6].

The low dosage of the adaptation exercises may have minimized the improvements observed in our study. Studies recommend that patients begin vestibular adaptation exercises with tolerable velocity, repetitions, and frequency then progress

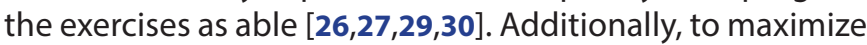
the benefits of vestibular adaptation exercises, it has been suggested they be designed to reflect the patient-specific function and environment [31]. The range of vestibular adaptation exercise programs has been reported as 3 to 10 weeks $[31,32]$.

Recommendations for future research include the inclusion of a standardized subjective assessment tool to quantify the degree of motion sensitivity and it's impact on activities of daily living. Also, more frequent direct observation of the vestibular adaptation exercise program to improve the quality of the exercise performance. Additionally, vestibular adaptation exercises should be progressed including velocity, amplitude, duration, frequency, and directionality of movements to determine if more gains are possible.

\section{Conclusion}

Results of this study suggest that a minimal dosage of vestibular adaptation exercises over a 6-week period improves postural stability in younger adults with sub-clinical chronic motion sensitivity. Further research is warranted to determine if additional exercise progression will result in increased gains. Older adult populations should also be included.

\section{Additional files}

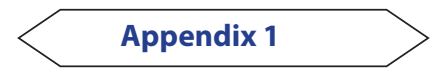

List of abbreviations

VOR: Vestibulo-ocular reflex

CDP-IVR: Computerized dynamic posturography with immersion virtual reality

SD: Standard deviation

SE: Standard error

BMI: Body mass index

\section{Competing interests}

The authors declare that they have no competing interests.

Authors' contributions

\begin{tabular}{|l|c|c|c|c|c|c|c|}
\hline Authors' contributions & DA & EJ & ND & SG & SD & TC & LZ \\
\hline Research concept and design & $\checkmark$ & $\checkmark$ & $\checkmark$ & $\checkmark$ & $\checkmark$ & $\checkmark$ & $\checkmark$ \\
\hline Collection and/or assembly of data & $\checkmark$ & $\checkmark$ & -- & $\checkmark$ & $\checkmark$ & -- & -- \\
\hline Data analysis and interpretation & $\checkmark$ & $\checkmark$ & $\checkmark$ & -- & -- & -- & -- \\
\hline Writing the article & $\checkmark$ & $\checkmark$ & -- & -- & -- & -- & -- \\
\hline Critical revision of the article & $\checkmark$ & $\checkmark$ & $\checkmark$ & $\checkmark$ & $\checkmark$ & $\checkmark$ & -- \\
\hline Final approval of article & $\checkmark$ & $\checkmark$ & $\checkmark$ & $\checkmark$ & $\checkmark$ & $\checkmark$ & $\checkmark$ \\
\hline Statistical analysis & $\checkmark$ & -- & $\checkmark$ & -- & -- & -- & -- \\
\hline
\end{tabular}

\section{Acknowledgement}

This study was supported by the Loma Linda University, Department of Physical Therapy as part of a Doctor of Science in Physical Therapy degree requirement for the primary author. The authors thank Abdullah Alismail for helping with the Qualtrics exercise program compliancy design.

Publication history

Editor: Gordon John Alderink, Grand Valley State University, USA. Received: 30-Oct-2015 Final Revised: 28-Dec-2015

Accepted: 01-Jan-2016 Published: 13-Jan-2016

\section{References}

1. Hanley K, O'Dowd T and Considine N. A systematic review of vertigo in primary care. Br J Gen Pract. 2001; 51:666-71. | Article | PubMed Abstract | PubMed FullText

2. Karatas M. Central vertigo and dizziness: epidemiology, differential diagnosis, and common causes. Neurologist. 2008; 14:355-64. | Article I PubMed

3. Badke MB, Miedaner JA, Shea TA, Grove CR and Pyle GM. Effects of vestibular and balance rehabilitation on sensory organization and dizziness handicap. Ann Otol Rhinol Laryngol. 2005; 114:48-54. | Article I PubMed

4. Akiduki $\mathrm{H}$, Nishiike S, Watanabe H, Matsuoka K, Kubo T and Takeda N. Visual-vestibular conflict induced by virtual reality in humans. Neurosci Lett. 2003; 340:197-200. | Article | PubMed

5. Bos JE, MacKinnon SN and Patterson A. Motion sickness symptoms in a ship motion simulator: effects of inside, outside, and no view. Aviat Space Environ Med. 2005; 76:1111-8. | Article | PubMed

6. Owen N, Leadbetter AG and Yardley L. Relationship between postural control and motion sickness in healthy subjects. Brain Res Bull. 1998; 47:471-4. | Article | PubMed

7. Cobb SV. Measurement of postural stability before and after immersion in a virtual environment. Appl Ergon. 1999; 30:47-57. | Article | PubMed

8. Cobb SV and Nichols SC. Static posture tests for the assessment of postural instability after virtual environment use. Brain Res Bull. 1998; 47:459-64. | Article | PubMed

9. Akin FW and Davenport MJ. Validity and reliability of the Motion Sensitivity Test. J Rehabil Res Dev. 2003; 40:415-21. | Article | PubMed

10. Herdman SJ. Anatomy and Physiology of the Normal Vestibular System. 3rd ed, Vestibular Rehabilitation. 2007; 2-18.

11. Schubert MC and Minor LB. Vestibulo-ocular physiology underlying vestibular hypofunction. Phys Ther. 2004; 84:373-85. | Article | PubMed

12. Demer JL and Amjadi F. Dynamic visual acuity of normal subjects during vertical optotype and head motion. Invest Ophthalmol Vis Sci. 1993; 34:1894-906. | Article | PubMed

13. Demer JL, Honrubia V and Baloh RW. Dynamic visual acuity: a test for oscillopsia and vestibulo-ocular reflex function. Am J Otol. 1994; 15:3407. | Article | PubMed

14. Herdman SJ. Role of vestibular adaptation in vestibular rehabilitation. Otolaryngol Head Neck Surg. 1998; 119:49-54. | Article | PubMed

15. Kathleen M and Gill-Body JC. Current Concepts in The Management Of Individuals With Vestibular Dysfunction. APTA Learning Center. 2011. | Book

16. Han $\mathrm{BI}$, Song $\mathrm{HS}$ and Kim JS. Vestibular rehabilitation therapy: review of indications, mechanisms, and key exercises. J Clin Neurol. 2011; 7:18496. | Article | PubMed Abstract | PubMed FullText

17. Shelhamer M, Tiliket C, Roberts D, Kramer PD and Zee DS. Short-term vestibulo-ocular reflex adaptation in humans. II. Error signals. Exp Brain Res. 1994; 100:328-36. | Article | PubMed

18. Giray M, Kirazli Y, Karapolat H, Celebisoy N, Bilgen C and Kirazli T. Short-term effects of vestibular rehabilitation in patients with chronic unilateral vestibular dysfunction: a randomized controlled study. Arch Phys Med Rehabil. 2009; 90:1325-31. | Article | PubMed 
19. Hall CD, Schubert MC and Herdman SJ. Prediction of fall risk reduction as measured by dynamic gait index in individuals with unilateral vestibular hypofunction. Otol Neurotol. 2004; 25:746-51. | PubMed

20. Morimoto H, Asai Y, Johnson EG, Lohman EB, Khoo K, Mizutani $Y$ and Mizutani T. Effect of oculo-motor and gaze stability exercises on postural stability and dynamic visual acuity in healthy young adults. Gait Posture. 2011; 33:600-3. | Article | PubMed

21. Bertec Corporation. 2014. | Website

22. Monsell EM, Furman JM, Herdman SJ, Konrad HR and Shepard NT. Computerized dynamic platform posturography. Otolaryngol Head Neck Surg. 1997; 117:394-8. | Article | PubMed

23. Palm HG, Lang P, Strobel J, Riesner HJ and Friemert B. Computerized dynamic posturography: the influence of platform stability on postural control. Am J Phys Med Rehabil. 2014; 93:49-55. | Article | PubMed

24. Ford-Smith CD, Wyman JF, Elswick RK, Jr., Fernandez T and Newton RA. Test-retest reliability of the sensory organization test in noninstitutionalized older adults. Arch Phys Med Rehabil. 1995; 76:7781. | Article | PubMed

25. Broglio SP, Sosnoff JJ, Rosengren KS and McShane K. A comparison of balance performance: computerized dynamic posturography and a random motion platform. Arch Phys Med Rehabil. 2009; 90:145-50. | Article | PubMed

26. Alrwaily $M$ and Whitney SL. Vestibular rehabilitation of older adults with dizziness. Otolaryngol Clin North Am. 2011; 44:473-96. | Article | PubMed

27. Herdman SJ. Exercise strategies for vestibular disorders. Ear Nose Throat J. 1989; 68:961-4. | Article | PubMed

28. Guerraz M, Yardley L, Bertholon P, Pollak L, Rudge P, Gresty MA and Bronstein AM. Visual vertigo: symptom assessment, spatial orientation and postural control. Brain. 2001; 124:1646-56. | Article | PubMed

29. Herdman SJ, Hall CD, Schubert MC, Das VE and Tusa RJ. Recovery of dynamic visual acuity in bilateral vestibular hypofunction. Arch Otolaryngol Head Neck Surg. 2007; 133:383-9. | Article | PubMed

30. Herdman SJ, Schubert MC, Das VE and Tusa RJ. Recovery of dynamic visual acuity in unilateral vestibular hypofunction. Arch Otolaryngol Head Neck Surg. 2003; 129:819-24. | Article | PubMed

31. Tee LH and Chee NW. Vestibular rehabilitation therapy for the dizzy patient. Ann Acad Med Singapore. 2005; 34:289-94. | Pdf | PubMed

32. Herdman SJ and Clendaniel RA. Physical therapy treatment of vestibular hypofunction. 4th ed, Vestibular Rehabilitation. 2014; 394-431.

\section{Citation:}

Alyahya D, Johnson EG, Daher NS, Gaikwad SB, Deshpande S, Cordett TK and Zidek L. Effect of vestibular adaptation exercises on chronic motion sensitivity: a randomized controlled trial. Phys Ther Rehabil. 2016; 3:1.

http://dx.doi.org/10.7243/2055-2386-3-1 